OPEN ACCESS

Edited by: Gionata De Vico,

University of Naples Federico II, Italy

Reviewed by:

Fagr Khamis Abdel-Gawad, National Research Centre, Egypt Brunella Restucci, University of Naples Federico II, Italy

*Correspondence: Maria V. Brundo mvbrundo@unict.it

Specialty section:

This article was submitted to

Aquatic Physiology,

a section of the journal

Frontiers in Physiology

Received: 10 January 2016

Accepted: 11 April 2016

Published: 29 April 2016

Citation:

Salvaggio A, Marino F, Albano M, Pecoraro R, Camiolo G, Tibullo D,

Bramanti V, Lombardo BM,

Saccone S, Mazzei V and Brundo MV (2016) Toxic Effects of Zinc Chloride on the Bone Development in Danio rerio (Hamilton, 1822).

Front. Physiol. 7:153

doi: 10.3389/fphys.2016.00153

\section{Toxic Effects of Zinc Chloride on the Bone Development in Danio rerio (Hamilton, 1822)}

\author{
Antonio Salvaggio ${ }^{1}$, Fabio Marino ${ }^{2}$, Marco Albano ${ }^{2}$, Roberta Pecoraro ${ }^{3}$, \\ Giuseppina Camiolo ${ }^{3}$, Daniele Tibullo ${ }^{3}$, Vincenzo Bramanti ${ }^{4}$, Bianca M. Lombardo ${ }^{3}$, \\ Salvatore Saccone ${ }^{3}$, Veronica Mazzei ${ }^{3}$ and Maria V. Brundo ${ }^{3 *}$ \\ ${ }^{1}$ Experimental Zoo-prophylactic Institute of Sicily, Catania, Italy, ${ }^{2}$ Department of Veterinary Science, University of Messina, \\ Messina, Italy, ${ }^{3}$ Department of Biological, Geological and Environmental Science, University of Catania, Catania, Italy, \\ ${ }^{4}$ Department of Biomedical and Biotechnological Sciences, University of Catania, Catania, Italy
}

The increase of heavy metals in the environment involves a high exposure of aquatic organisms to these pollutants. The present study is planned to investigate the effects of zinc chloride $\left(\mathrm{ZnCl}_{2}\right)$ on the bone embryonic development of Danio rerio and confirm the use of zebrafish as a model organism to study the teratogenic potential of this pollutant. Zebrafish embryos were exposed to different $\mathrm{ZnCl}_{2}$ concentrations and analyzed by ICP-MS. The skeletal anomalies were evaluated to confocal microscope after staining with calcein solution and RhodZin ${ }^{\mathrm{TM}}-3, \mathrm{AM}$. The data show a delay in hatching compared with the controls, malformations in the process of calcification and significant defects in growth. In conclusion, the current work demonstrates for the first time the Zn toxic effects on calcification process and confirm zebrafish (Danio rerio) as suitable alternative vertebrate model to study the causes and the mechanisms of the skeletal malformations.

Keywords: zebrafish, zinc chloride, bone development, skeletal malformations, calcein

\section{INTRODUCTION}

In recent years, there has been an increasing ecological and global public health concern associated with environmental contamination by heavy metals. Aquatic organisms are exposed to a significant amount of pollutants, especially to heavy metals derived from geogenic, industrial, agricultural, pharmaceutical, and domestic effluents (Heath, 1987) that lead to biochemical disturbances (Dethloff et al., 1999; Orun and Talas, 2008; De Domenico et al., 2011; Copat et al., 2012; Guerriero et al., 2014; Fasulo et al., 2015).

Environmental contamination can also occur through metal corrosion, atmospheric deposition, soil erosion of metal ions, and leaching of heavy metals, sediment re-suspension, and metal evaporation from water resources to soil and ground water (Skidmore, 1965). Natural phenomena such as weathering and volcanic eruptions have also been reported to significantly contribute to heavy metal pollution (Fergusson, 1990; Goyer, 2001; Bradl, 2002).

Since heavy metals are required for various biological process but are also toxic at high levels, they represent an interesting object of research.

The Zinc $(\mathrm{Zn})$ is an essential element for organisms and plays an important role in aquatic physiological processes (Watanabe et al., 1997). However, excessive $\mathrm{Zn}$ in the aquatic environments is toxic (Huang et al., 2010; Zheng et al., 2011). The fish toxicity by Zn has been well documented in various fish species (Dautremepuits et al., 2004; Giardina et al., 2009). 

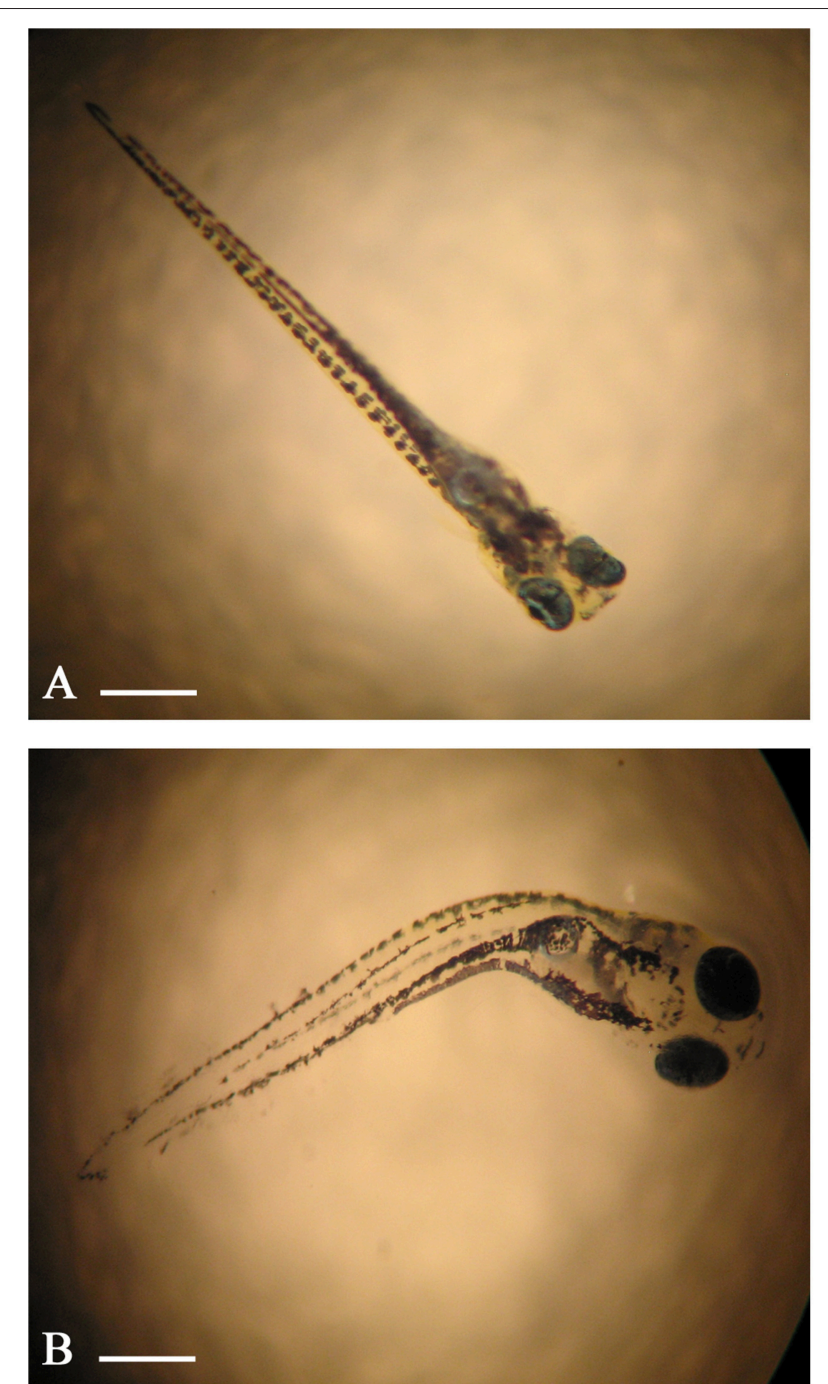

FIGURE 1 | Embryo zebrafish observed with the stereomicroscope. (A) Larvae treated with $10 \mathrm{mg} / \mathrm{L}$ of $\mathrm{ZnCl}_{2}$; curvatures of the spine are not evident. (B) Larva treated with $200 \mathrm{mg} / \mathrm{L}$ of $\mathrm{ZnCl}_{2}$ with pronounced curvature of the spine. Scale bar: $(\mathbf{A})=100 \mu \mathrm{m} ;(\mathbf{B})=120 \mu \mathrm{m}$.

Relatively little attention has been paid to zinc's role in human nutrition and health (Skidmore, 1965). The Zinc may play a role in various biological processes, such as in enzyme activities, cell structures, protein structures, and carbohydrate metabolism in the fishes. Physiological and biochemical alterations were reported in the early life stage (ELS) of fishes after exposure to $\mathrm{Zn}$, such as chorion structure and permeability changes and inhibition of enzyme activities in organs (Küçükoğlu et al., 2013). Zinc toxicity changes during the course of embryonic development of fish; in fact, embryonic toxicity in the absence of chorion was greater than in its presence. In addition, zinc toxicity to the ELS of fishes can be easily influenced by water properties such as temperature, dissolved oxygen concentration, hardness, $\mathrm{pH}$, salinity, osmoregulation, and water permeability (Guner, 2010; Zhu et al., 2012).
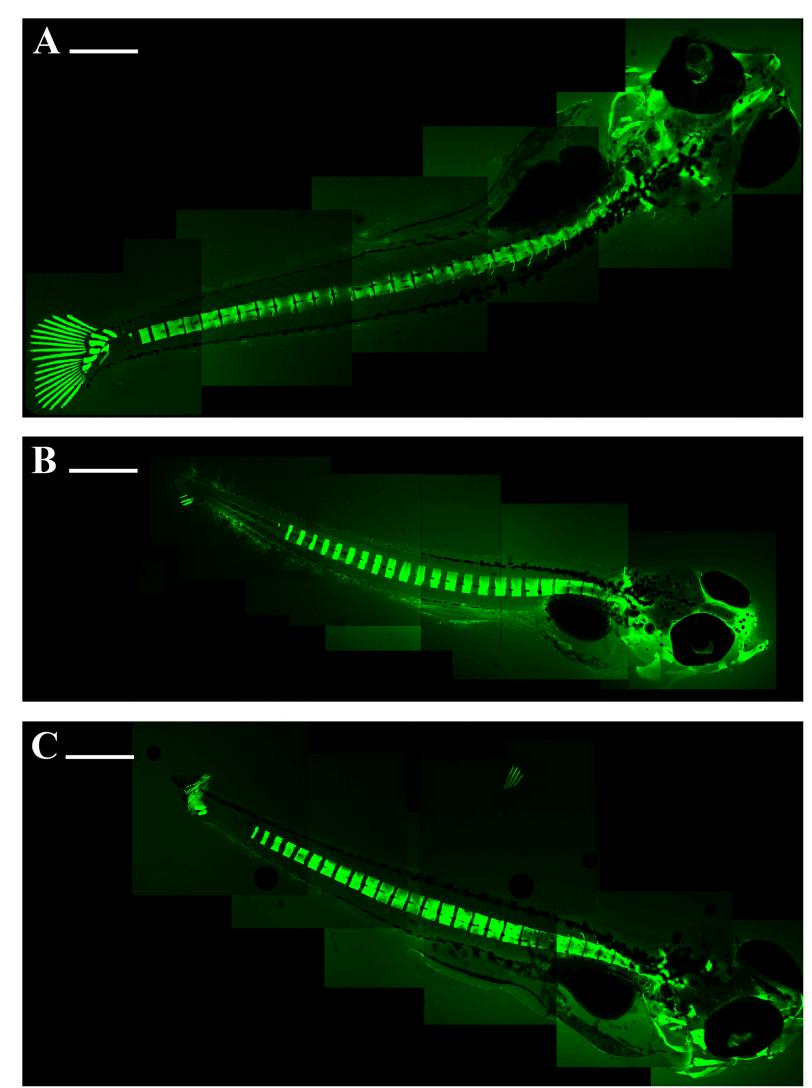

FIGURE 2 | Embryo zebrafish 15 days treated with calcein solution. The decalcification of the vertebrae is evident; the gill arches and caudal fins show more damage with increasing concentration. Composite images of the embryos were assembled with Adobe Photoshop 5.0. (A) $50 \mathrm{mg} / \mathrm{L}$; (B) $100 \mathrm{mg} / \mathrm{L} ;$ (C) $200 \mathrm{mg} / \mathrm{L}$. Scale bar: $500 \mu \mathrm{m}$.

This study was planned to investigate the effect of $\mathrm{ZnCl}_{2}$ on the bone embryonic development of zebrafish and to determine if it could represent a model for investigation ofteratogenic potential of environmental pollutants.

Danio rerio is a model vertebrate extensively used in scientific investigation worldwide (Zhu et al., 2012; Alsop and Wood, 2013; Howe et al., 2013; Yin et al., 2014). The US Environmental Protection Agency in fact designated zebrafish as a powerful vertebrate model for assessing environmental contaminants and itwas selected to evaluate the toxicity during development. In the last decades, protocols and techniques have been developed in order to evaluate the effects of chemicals at different levels of biological organization of this species and to evaluate the lethal and sub-lethal effects of pollutants.

\section{MATERIALS AND METHODS}

\section{Zebrafish Embryos}

All experiments have been carried out at Centre for Experimental Fish Pathology of Sicily (CISS), University of Messina, Establishment for Users recognized by the Italian Ministry 

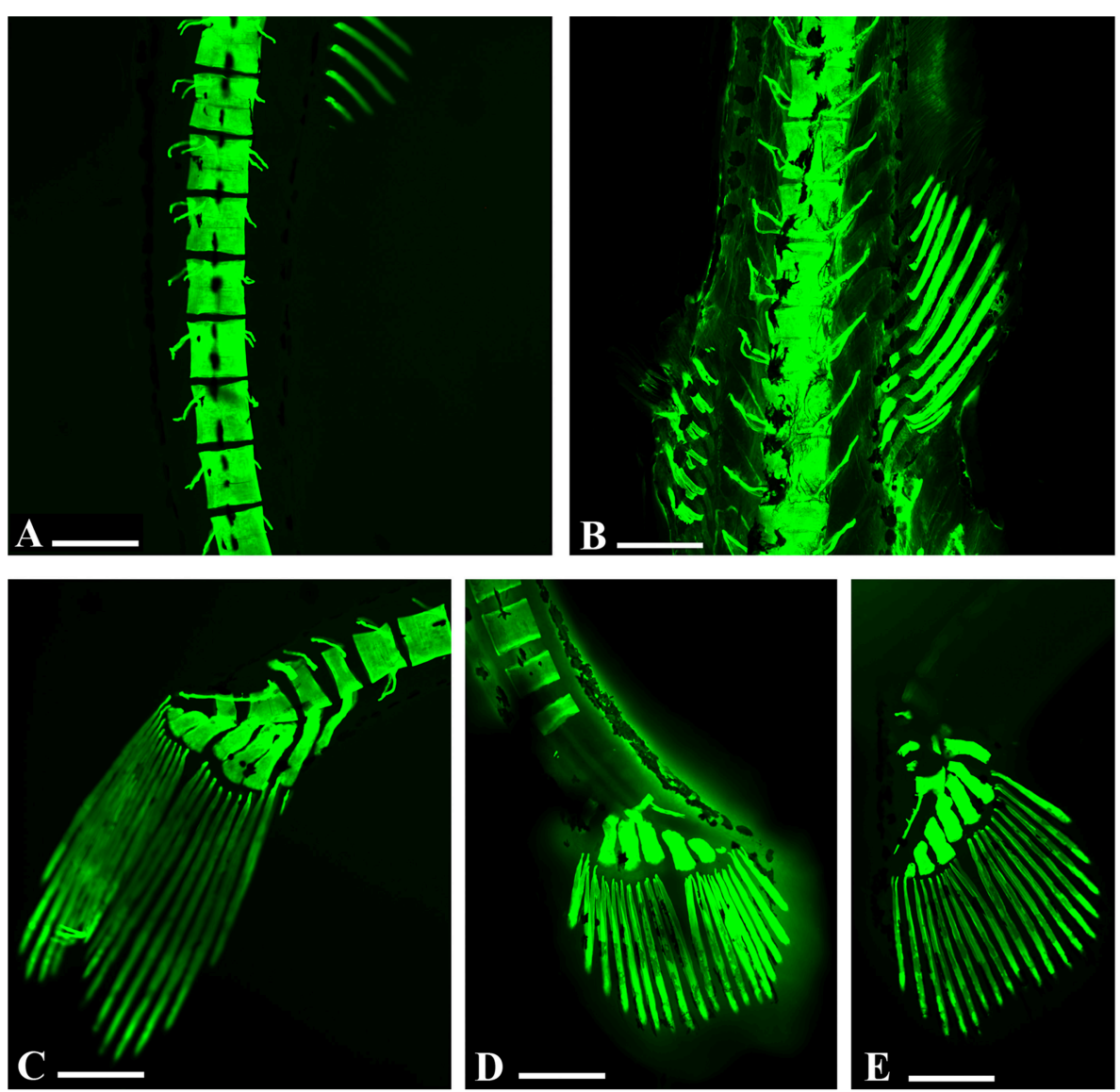

FIGURE 3 | Embryo zebrafish treated with calcein solution. (A,B) Particularly abnormalities in vertebral spines in samples treated with $200 \mathrm{mg} / \mathrm{L}$. (A) Zebrafish embryos 16 days. (B) Zebrafish embryos 21 dpf. (C-E) Zebrafish embryos 16 days. Details of the abnormalities of the caudal rays with clear areas of decalcification of caudal vertebrae related to the concentrations tested. (C) $50 \mathrm{mg} / \mathrm{L}$; (D) $100 \mathrm{mg} / \mathrm{L} ;$ (E) $200 \mathrm{mg} / \mathrm{L}$. Scale bar: $200 \mu \mathrm{m}$.

of Health, according to the Italian Law D.L. 2014, $\mathrm{n}^{\circ} 26$, in application of the $2010 / 63 /$ UE. This project had been registered with the serial number CISS/17/2013 and had been authorized according to the former National Law D.L. $116 / 92$.

The study was conducted in wild-type zebrafish embryos kept, reproduced and contaminated within a plant "Zebtec Tecniplast Stand Alone" at the CISS. After the pairing of one male with two females and the spawning, contaminated and control embryos were evaluated as described by Westerfield (1995) and Kimmel et al. (1995).

\section{Exposure Procedures}

Three Hundred embryos, in three repetitions, were exposed to different $\mathrm{ZnCl}_{2}$ concentrations for 21 days starting from zygote stage. In order to determine the range of $\mathrm{ZnCl}_{2}$, threshold tests were performed and we used the following $\mathrm{ZnCl}_{2}$ concentrations: $200,150,100,50,25,10,5,2.5,1$, and $0.5 \mathrm{mg} / \mathrm{L}$. The control samples (30 larvae in three repetitions) were kept in water, in the same conditions. The larvae were analyzed with Leica M205C microscope.

\section{Calcein Solutions}

Calcein solution $(0.2 \%)$ was prepared by dissolving $2 \mathrm{~g}$ of calcein powder (Sigma, Life Sciences) in 1 liter of deionized water. Due to calcein's strong acidifying effects, an appropriate amount of Sodium hydroxide $(\mathrm{NaOH} ; 0.5 \mathrm{~N})$ was added to the solution to have the $\mathrm{pH}$ 7.4. Treated zebrafish embryos were netted and immersed in the solutions in Petri dishes for $10 \mathrm{~min}$. After the immersions, the embryos were rinsed in fresh water for $10 \mathrm{~min}$ in order to eliminate the excess of calcein. The embryos were then euthanized in 3\% solution of tricaine-methanesulfonate (MS222) and mounted on glass slides. Vectashield mounting medium (Vector Laboratories, Inc., Burlingame, CA, USA). Observations were carried out using confocal laser scanning microcopy (CLSM; Zeiss LSM 700), equipped with the ZEN-2011 software.

\section{Staining with Rhodzin ${ }^{\mathrm{TM}}-3, \mathrm{AM}$}

Some larvae, after having been treated with calcein, were anesthetized and fixed in a solution of $3.7 \%$ formaldehyde $(\mathrm{pH}$ 7.0), for $45 \mathrm{~min}$. After washing in PBS, the samples were treated with Triton $1 \mathrm{X}$, incubated for $20 \mathrm{~min}$ in a blocking solution and 
after incubated for $1 \mathrm{~h}$ with RhodZin ${ }^{\mathrm{TM}}-3, \mathrm{AM}$ (INVITROGEN, 1:4) in the dark. After repeated washing, the samples were mounted on glass slides. Vectashield mounting medium (Vector Laboratories, Inc., Burlingame, CA, USA). The observations were made using confocal laser scanning microcopy (CLSM; Zeiss LSM 700), equipped with the ZEN-2011 software.

\section{Zinc Analysis}

Zinc concentrations in larvae were determined byInductively Coupled Plasma Mass Spectrometry (ICP-MS). Samples were digested in $65 \%$ Nitric acid $\left(\mathrm{HNO}_{3}\right.$; Carlo Erba Chemicals) overnight. After digestion, the samples were diluted by the addition of ultra-pure water (Merck) and analyzed by ICP-MS and compared with standards.

\section{Statistical Analysis}

Statistical analysis was made with Prism Software (Graphpad Software Inc., La Jolla, CA, USA). Data were expressed as mean or $S D$. Statistical analysis was carried out by two-way ANOVA test. A p-value of 0.05 was considered to indicate a statistically significant difference between experimental and control groups.

\section{RESULTS}

The exposure to $\mathrm{ZnCl}_{2}$ induced a delay in hatching compared with the controls in a concentration-dependent manner. At concentrations $>200$, the $100 \%$ of the eggs not haching from the chorion. At the $200 \mathrm{mg} / \mathrm{L}$ of $\mathrm{ZnCl}_{2}$ the hatching from the chorion was failed in $90 \%$ of fertilized eggs.

After contamination with increasing concentrations of $\mathrm{ZnCl}_{2}$ skeletal malformations can be observed without histochemical assay because of the transparency of embryos $D$. rerio. These anomalies were not observed at lower concentrations (0.5$25 \mathrm{mg} / \mathrm{L}$; Figure 1A), whereas the treatment with the higher concentrations (50-200 mg/L) of $\mathrm{ZnCl}_{2}$ induced abnormalities of the spine with lateral curvature similar to a scoliosis (Figure 1B). Moreover, the fishes treated with $\mathrm{ZnCl}_{2}$ showed a different size in a concentration-dependent manner highlighting defects in growth.

The skeletal anomalies were evaluated to confocal microscope after staining with calcein solution and RhodZin ${ }^{\mathrm{TM}}-3, \mathrm{AM}$. No fluorescent signals could be detected in embryos up to 4 days post-fertilization (dpf). First fluorescent signals became apparent in 5-dpf embryos and were restricted to the head. The calcein staining of axial skeleton in the trunk region first appeared on day 7-dpf.

The fusion of the hemal spinal with caudal axis was identified in embryos contaminated with $\mathrm{Zn}$. Skeletal abnormalities, like kyphosis, were observed in fifth cranial vertebrae, in first prehemal arch and in fifth-sixth hemal arches (Figures 2A-C).

We observed alterations in the vertebral spine (Figures $\mathbf{3 A}, \mathbf{B}$ ), in the caudal fin (Figures 3C-E) and in some bones of the skull such as in the premaxillary and dental bones, with a considerable tapering snout (Figure 4A).

Incubation with RhodZin ${ }^{\mathrm{TM}}-3, \mathrm{AM}$, indicated that the alterations affecting the skeletal system seems to be linked to a
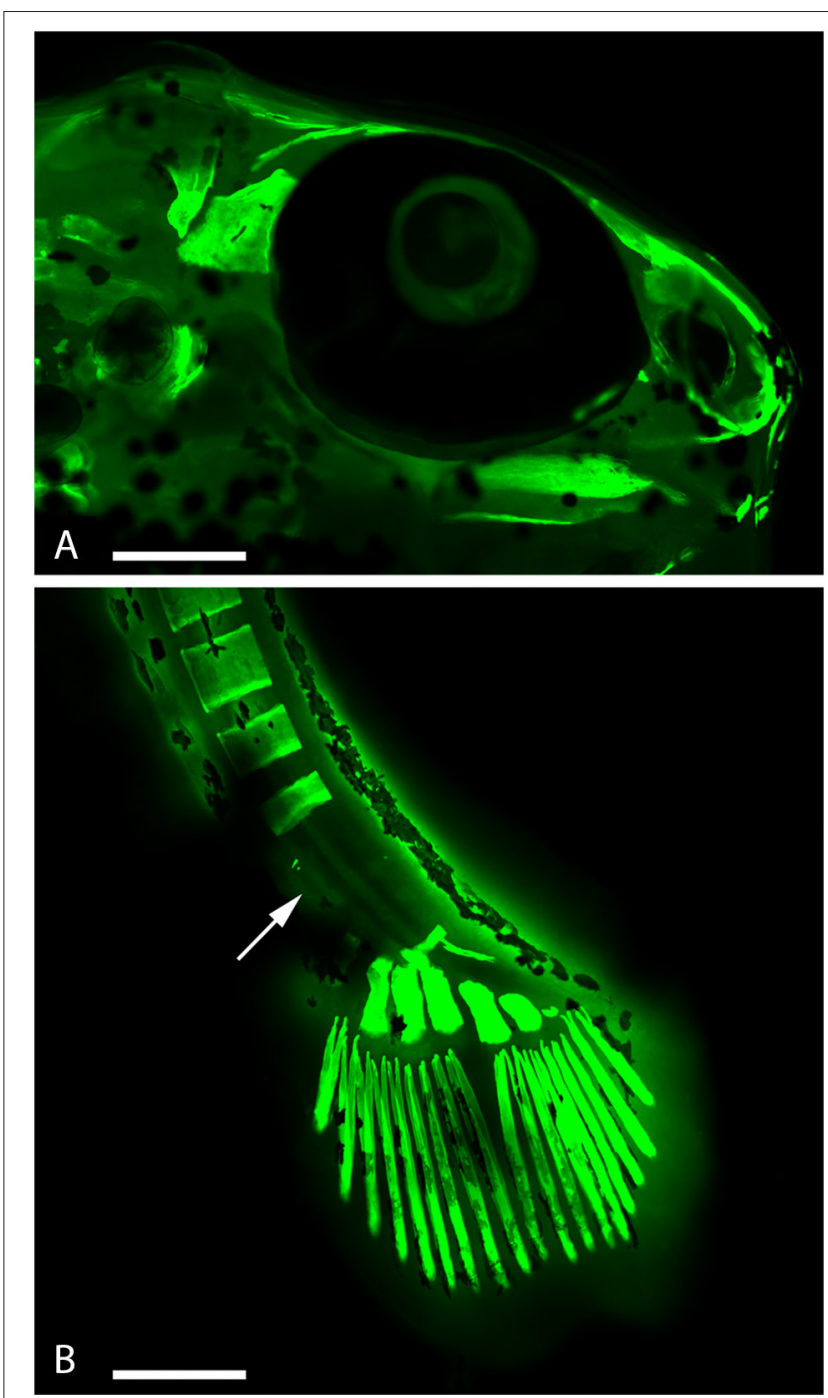

FIGURE 4 | Embryo zebrafish treated with calcein solution and RhodZin $^{\text {TM }}$-3,AM. (A) It is evident a considerable tapering of the muzzle. (B) Presence of zinc in the areas of decalcification (arrow). Scale bar: $200 \mu \mathrm{m}$.

decreased calcification because of the replacing of calcium with zinc (Figure 4B).

The ICP-MS analysis was used to evaluate the $\mathrm{Zn}$ levels. We observed that $25 \mathrm{mg} / \mathrm{L} \mathrm{ZnCl}_{2}$ did not modify the $\mathrm{Zn}$ levels in larvae respect to control (untreated group; Figure 5). At higher concentrations (50 and $150 \mathrm{mg} / \mathrm{L}$ ) after 7 days we observed a significant increase of the levels of $\mathrm{Zn}$ respect to untreated samples (CTRL) in a dose dependent manner $(p<0.0001$; Figure 5).

\section{DISCUSSION}

Although the toxicity of zinc to several fish species has been documented, the toxicity of this metal is not well-known for all aquatic organisms (Küçükoğlu et al., 2013). Nevertheless, a 


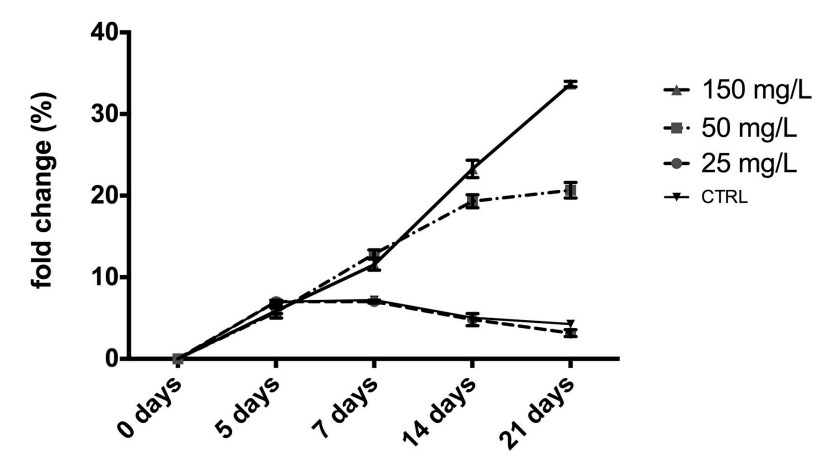

FIGURE 5 | Fold change of zinc concentrations in zebrafish embryos (mean \pm SD). The samples contaminated with low concentrations of $\mathrm{ZnCl}_{2}$ $25 \mathrm{mg} / \mathrm{L}$, do not present differences with the control samples (untreated); athigher concentrations (50 and $150 \mathrm{mg} / \mathrm{L}$ of $\mathrm{ZnCl}_{2}$ ) the $\mathrm{Zn}$ levels was increased after 7 days of contamination $(p<0.0001)$ respect to control $(p<$ 0.0001). Values are expressed as a mean $\pm S D$ of four independent experiments performed in triplicate. Statistically significant differences by two-way analysis of variance (ANOVA) were performed.

number of studies have indicated that zinc toxicity is speciesspecific and varies with developmental stages (Ho et al., 2012). In this study we showed cytoskeleton an modifications induced by $\mathrm{Zn}$ exposure in Zebrafish, demonstrating also that $D$. rerio is a good animal model for these investigations.

The inhibition of DNA synthesis is the most likely explanation of $\mathrm{Zn}$ teratogenicity but the specific mechanism is unknown (Jakovac et al., 2015). Some authors affirmed that in mammals an excessive amount of zinc chloride is little teratogenic to due to protective mechanisms of the maternal liver and metalloenzymes (Küçükoğlu et al., 2013), while for a oviparous aquatic organisms, not having no protection, an excessive amount of zinc chloride may cause an abnormal development (Nagel, 2002). Our data showed that environmental factors may induce skeletal

\section{REFERENCES}

Alsop, D., and Wood, C. M. (2013). Metal and pharmaceutical mixtures: is ion loss the mechanism underlying acute toxicity and widespread additive toxicity in zebrafish? Aquat. Toxicol. 140-141, 257-267. doi: 10.1016/j.aquatox.2013.05.021

Bradl, H. (2002). Heavy Metals in the Environment: Origin, Interaction and Remediation, Vol. 6. London: Academic Press.

Copat, C., Brundo, M. V., Arena, G., Grasso, A., Oliveri Conti, G., Ledda, C., et al. (2012). Seasonal variation of bioaccumulation in Engraulis encrasicolus (Linneaus, 1758) and related biomarkers of exposure. Ecotoxicol. Environ. Saf. 86, 31-37. doi: 10.1016/j.ecoenv.2012. 09.006

Dautremepuits, C. S., Paris-Palacios, S., Betoulle, S., and Vernet, G. (2004). Modulation in hepatic and head kidney parameters of carp (Cyprinus carpio L.) induced by copper and chitosan. Comp. Biochem. Physiol. C Toxicol. Pharmacol. 137, 325-333. doi: 10.1016/j.cca.2004.03.005

De Domenico, E., Mauceri, A., Giordano, D., Maisano, M., Gioffrè, G., Natalotto, A., et al. (2011). Effects of "in vivo" exposure to toxic sediments on juveniles of sea bass (Dicentrarchus labrax). Aquat. Toxicol. 105, 688-697. doi: 10.1016/j.aquatox.2011.08.026

Dethloff, G. M., Schlenk, D., Hamm, J. T., and Bailey, H. C. (1999). “Alteration in physiological parameters of rainbow trout (Oncorhynchus mykiss) with malformations (Du et al., 2001) as well as shown from high rate of morphological alterations identified in our vivo model.

The calcification process in zebrafish was found to progress from the anterior to posterior regions in a segmented fashion as the embryos developed. It was interesting to note that the anterior-to-posterior calcification process of vertebrae was not continuous, but instead appeared to be divided into two distinct domains: an anterior domain and a posterior domain. The rationale for dividing them into two domains is based on observations that vertebrae numbers 2 and 3 were always calcified later in time than vertebrae 4 (Du et al., 2001). Calcification process was interrupted in some vertebral areas after Zn exposure. Furthermore, abnormalities were detected also in the bone of the skull, in particular, in premaxillary and dental bones with a considerable tapering snout, because of what the eyes of some larvae looked more large.

It has been demonstrated that zinc induces defects in the hemiarches, dorsal-base, and ventral-base leading to torsion and scoliosis of the spine (Du et al., 2001). We observed that substitution of calcium with zinc in the bone induced a curvature of the spine (scoliosis) more evident during the various stages of development.

In conclusion, the current work demonstrates for the first time the $\mathrm{Zn}$ toxic effects on calcification process and confirms zebrafish (D. rerio) as ideal alternative vertebrate model to study the causes and the mechanisms of the skeletal malformations.

\section{AUTHOR CONTRIBUTIONS}

AS, FM, and MVB developed the research idea and experimental design. MA managed fish facility. RP and GC conducted experiments. $\mathrm{BL}$ made the statistical analysis. SS made the pictures to the confocal. AS, VM, MVB, DT, and VB co-wrote the manuscript and all authors read and approved the final manuscript.

exposure to copper and copper/zinc mixtures." Ecotoxicol. Environ. Saf. 42, 253-264. doi: 10.1006/eesa.1998.1757

Du, S. J., Frenkel, V.,Kindschi, G., and Zohar, Y. (2001). Visualizing normal and defective bone development in zebrafish embryos using the fluorescent chromophore calcein. Dev. Biol. 238, 239-246. doi: 10.1006/dbio.2001. 0390

Fasulo, S., Guerriero, G., Cappello, S., Colasanti, M., Schettino, T., Leonzio, C., et al. (2015). The "SYSTEMS BIOLOGY" in the study of xenobiotic effects on marine organisms for evaluation of the environmental health status: biotechnological applications for potential recovery strategies. Rev. Environ. Sci. Biotechnol. 14, 339-345. doi: 10.1007/s11157-0159373-7

Fergusson, J. E. (1990). The Heavy Elements: Chemistry, Environmental Impact and Health Effects. Oxford: Pergamon Press.

Giardina, A., Larson, S. F., Wisner, B., Wheeler, J., and Chao, M. (2009). Longterm and acute effects of zinc contamination of a stream on fish mortality and physiology. Environ. Toxicol. Chem. 28, 287-295. doi: 10.1897/07-461.1

Goyer, R. A. (2001). "Toxic effects of metals", in Cassarett and Doull's Toxicology: The Basic Science of Poisons, ed C. D. Klaassen (New York, NY: McGraw-Hill Publisher), 811-867.

Guerriero, G., Trocchia, S., Abdel-Gawad, F. K., and Ciarcia, G. (2014). Roles of reactive oxygen species in the spermatogenesis regulation. Front. Endocrinol. 5:56. doi: 10.3389/fendo.2014.00056 
Guner, U. (2010). Heavy metal effects on $\mathrm{P}, \mathrm{Ca}, \mathrm{Mg}$, and total protein contents in embryonic pleopodal eggs and stage-1 juveniles of freshwater crayfish Astacus leptodactylus (Eschscholtz, 1823). Turk. J. Biol. 34, 405-412. doi: 10.3906/biy0811-19

Heath, A. G. (1987). Water Pollution and Fish Physiology. (Boca Raton, FL: CRC Press), 245.

Ho, E., Dukovcic, S., Hobson, B., Wong, C. P., Miller, G., Hardin, K., et al. (2012). Zinc transporter expression in zebrafish (Danio rerio) during development. Comp. Biochem. Physiol. C Toxicol. Pharmacol. 155, 26-32. doi: 10.1016/j.cbpc.2011.05.002

Howe, K., Clark, M. D., Torroja, C. F., Torrance, J., Berthelot, C., Muffato, M., et al. (2013). The zebrafish reference genome sequence and its relationship to the human genome. Nature 496, 498-503. doi: 10.1038/nature12111

Huang, W., Cao, L., Shan, X.,Xiao, Z.,Wang, Q., and Dou, S. (2010). Toxic effects of zinc on the development, growth, and survival of red sea bream Pagrus major embryos and larvae. Arch. Environ. Contam. Toxicol. 58, 140-150. doi: 10.1007/s00244-009-9348-1

Jakovac, H.,Grebić, D., Mrakovcic-Šutić, I., Rukavina, D., and Radošević-Stašić, B. (2015). Expression of metallothioneins in placental and fetal tissues in undisturbed and PGM-Zn treated syngeneic pregnancy. AJBIO 3, 1-7. doi: 10.11648/j.ajbio.s.2015030202.12

Kimmel, C. B., Ballard, W. W., Kimmel, S. R., Ullmann, B., and Schilling, T. F. (1995). Stages of embryonic development of the zebrafish. Dev. Dyn. 203, 253-310. doi: 10.1002/aja.1002030302

Küçükoğlu, M., Binokay, U. S., and BoğaPekmezekmek, A. (2013). The effects of zinc chloride during early embryonic development in zebrafish (Brachydanio rerio). Turk. J. Biol. 37, 158-164. doi: 10.3906/biy-1203-27

Nagel, R. (2002). Dar T: the embryo test with the zebrafish Danio rerio: a general model in ecotoxicology and toxicology. Altex 19, 38-48.

Orun, I., and Talas, Z. S. (2008). Antioxidative role of sodium selenite against the toxic effect of heavy metals $\left(\mathrm{Cd}^{2+}, \mathrm{Cr}^{3+}\right)$ on some biochemical and hematological parameters in the blood of rainbow trout (Oncorhynchus mykiss Walbaum, 1792). Fresenius Environ. Bull. 17, 1242-1246.

Skidmore, J. F. (1965). Resistance to zinc sulphate of the zebrafish (Brachydanio rerio Hamilton-Buchanan) at different phases of its life history. Ann. Appl. Biol. 56, 47-53. doi: 10.1111/j.1744-7348.1965.tb0 1214.x

Watanabe, Y., Oozeki, Y., and Kitagawa, D. (1997). Larval parameters determining preschooling juvenile production of pacific saury (Cololabis saira) in the northwestern Pacific. Can. J. Fish. Aquat. Sci. 54, 1067-1076. doi: 10.1139/f97013

Westerfield, M. (1995). The Zebrafish Book. A guide for the laboratory use of zebrafish (Danio rerio). Eugene, OR: University of Oregon Press.

Yin, X., Wang, H., Zhang, Y., Dahlgren, R. A., Zhang, H., Shi, M., et al. (2014). Toxicological assessment of trace $\beta$-diketone antibiotic mixtures on zebrafish (Danio rerio) by proteomic analysis. PLOS ONE 9:e102731. doi: 10.1371/journal.pone.0102731

Zheng, J. L., Luo, Z., Chen, Q. L., Liu, X., Liu, C. X., Zhao, Y. H., et al. (2011). Effect of waterborne zinc exposure on metal accumulation, enzymatic activities and histology of Synechogobius hasta. Ecotoxicol. Environ. Saf. 74, 1864-1873. doi: 10.1016/j.ecoenv.2011.06.018

Zhu, X., Tian, S., and Cai, Z. (2012). Toxicity assessment of iron oxide nanoparticles in zebrafish (Danio rerio) early life stages. PloS ONE 7:e46286. doi: 10.1371/journal.pone.0046286

Conflict of Interest Statement: The authors declare that the research was conducted in the absence of any commercial or financial relationships that could be construed as a potential conflict of interest.

The reviewer BR and handling Editor declared their shared affiliation, and the handling Editor states that the process nevertheless met the standards of a fair and objective review.

Copyright (c) 2016 Salvaggio, Marino, Albano, Pecoraro, Camiolo, Tibullo, Bramanti, Lombardo, Saccone, Mazzei and Brundo. This is an open-access article distributed under the terms of the Creative Commons Attribution License (CC BY). The use, distribution or reproduction in other forums is permitted, provided the original author(s) or licensor are credited and that the original publication in this journal is cited, in accordance with accepted academic practice. No use, distribution or reproduction is permitted which does not comply with these terms. 